\title{
Level of manifestation and connection between productivity of height of plants and resistance to lodging of winter barley in Forest-steppe
}

\author{
O. Demydov, \\ S. Vasylkivskiy, \\ Doctors of Agricultural Sciences \\ V. Gudzenko, \\ Candidate of Agricultural Sciences \\ The V. M. Remeslo Myronivka Institute of Wheat of National Academy of Agrarian Sciences
}

The purpose. To determine the level of manifestation and connection of productivity, height of plants and resistance to lodging of winter barley in central Forest-steppe of Ukraine. To select grades with optimum ratio of the named parameters. Methods. Field - standard for selection of eared cultures, statistical - dispersive, variation, correlation and graphic analyses with the use of programs Excel 2010 and Statistica 6.0. Results. On the basis of long-term researches $(2012-2016)$ of 29 genotypes of winter barley they fixed positive connection of productivity and resistance to lodging $(r=0,5880)$ and negative between latter and height of plants $(r=-0,6697)$, and also absence of correlation $(r=-0,1044)$ between productivity and height of plants. Grades are selected which considerably exceed the national standard on productivity and combine it with the increased resistance to lodging - Cartel, Paladin Mironovskiy, Atlant Mironovskiy. Conclusions. The opportunity of combination selection by increased and more stable level of manifestation of productivity of winter barley winter is proved at simultaneous decrease in height of plants and improvement of resistance to lodging. New grades with the best combination of the studied attributes which should be introduced in production in Forest-steppe are selected. They also may be used as valuable genetic source for creation of new initial stock.

Key words: winter barley, grade, productivity, height of plants, resistance to lodging, correlation.

In Ukraine since 2008, there has been noted an increase in agricultural producers' interest in winter barley culture. This is convincingly indicated by increase in sowing areas from $t$ traditional 300-400 thousand hectares to 1.0-1.2 million hectares [1]. Today, due to biological benefits of winter barley (higher productivity; early ripening thus giving the first cash receipts before winter wheat harvesting. facilitating decongest machinery during harvest, and serving as a good preceding crop for winter rape, after harvest sowing buckwheat or other crops; the possibility of later sowing in comparison with wheat, etc.) it is grown not only in the southern regions of our state, but also in the Forest-Steppe (Lisostep) and Woodland (Polissia) zone.

At the same time, the expansion of areas under the crop in the northern regions of the country raises the problem of creating varieties adapted to the conditions of these regions. It is convincingly proved that adaptive potential of a variety significantly depends on the conditions during plant breeding [2, 3]. Winter barley breeding in Ukraine on scientific basis at sufficient levels is carried out only at the Plant Breeding \& Genetic Institute - National Center of Seed and Cultivar Investigation (PBGI-NCSCI) and at the V. M. Remeslo Myronivka Institute of Wheat of NAAS (MIW) [4, 5]. At the MIW substantial winter barley research in the Forest-Steppe of Ukraine has been started in 1971. During this time, eight varieties of typical winter growth habit and four ones of alternative habit have been created, followed by the State registration. Another six varieties in 2016 are being under the State Variety Testing. Despite this, the weather conditions of recent years are marked by significant fluctuations of hydrothermal parameters [6]. This requires an assessment of their impact on different genotypes in order to identify the most pressing problems to be addressed by breeding efforts in order to create winter barley varieties with combination of increased productivity potential and genetic protection against abiotic and biotic factors.

Long-term own experimental research and a number of scientific publications indicate that study of expression level of plant height and lodging resistance is important issue in implementing the productivity potential of winter barley varieties [7-9].

The purpose. To determine expression level and relationship between yield, plant height, and lodging resistance of winter barley in the Forest-Steppe of Ukraine. To identify varieties with optimal ratio of these parameters. 
Materials and methods. The experiments were carried out in breeding crop rotation of MIW during 2012-2016 in accordance to conventional methods [10]. 29 varieties of different ecological origin representing different periods of breeding work we studied. In particular, these were varieties that have been put on the State Register of Ukraine until 2000: Bemir 2, Radon, Myronivskyi 87 (MYR 87), Pallidum 77 (MIW), Odeskyi 165 (Od. 165), Rosava, Taman, Osnova and Manas (PBGI-NCSCI); Oneha and Yuhodar (Crimean State Plant Breeding Experimental Station of NAAS), Tsyklon (Krasnodar Agricultural Research Institute named after P. P. Lukianenko); Kromoz, Luxor (Czech Republic); MIW varieties which were tested, but were not put on the State Register: Myronivskyi 93 (MYR 93) and Rytsar; MIW varieties which have been put on the State Register for the period 2006-2010: Borysfen, Kovcheh, Seim, Tutankhamon, Zuben, Zherar (National Standard of Ukraine since 2011); new MIW varieties (in the Register since 2014): Atlant Myronivskyi (Atlant) and Paladin Myronivskyi (Paladin); modern Western European varieties: Salamandra, Cartel, Nektaria (France); Wintmalt, Maskara (Germany). The genotypes studied also differ in systematic characters (multi-row and two-rowed (Atlant, Salamandra, Nektaria, Wintmalt, Maskara), growth habit (typically winter and alternative (Odeskyi 165, Rosava, Taman, Osnova, Kovcheh, Seim, Tutankhamon, Zuben)), cropping season duration, plant height, etc.

Research results. Weather conditions of cropping seasons of winter barley in 2011-2016 were characterized by significant deviations of hydrothermal indices from the average annual ones, which allowed to comprehensively assess the level of expression and variation of traits (Fig. 1, 2).

The level of yield in these years significantly varied, as evidenced by the data presented in Fig. 3 and in the Table 1. Its highest value on average in the experiment was noted in $2015-6.38 \mathrm{t} / \mathrm{ha}$, the least in 2014 and $2013-4.44$ and 4.53 t/ha respectively. On average, for the last five years, the varieties Cartel and Paladin Myronivskyi have significantly exceeded the others. In addition the variety Atlant Myronivskyi also significantly exceeded the national standard variety Zherar. These genotypes were characterized with more stable level of yield as higher in comparison with others the minimum value $(\mathrm{min})$ of yield indicated.

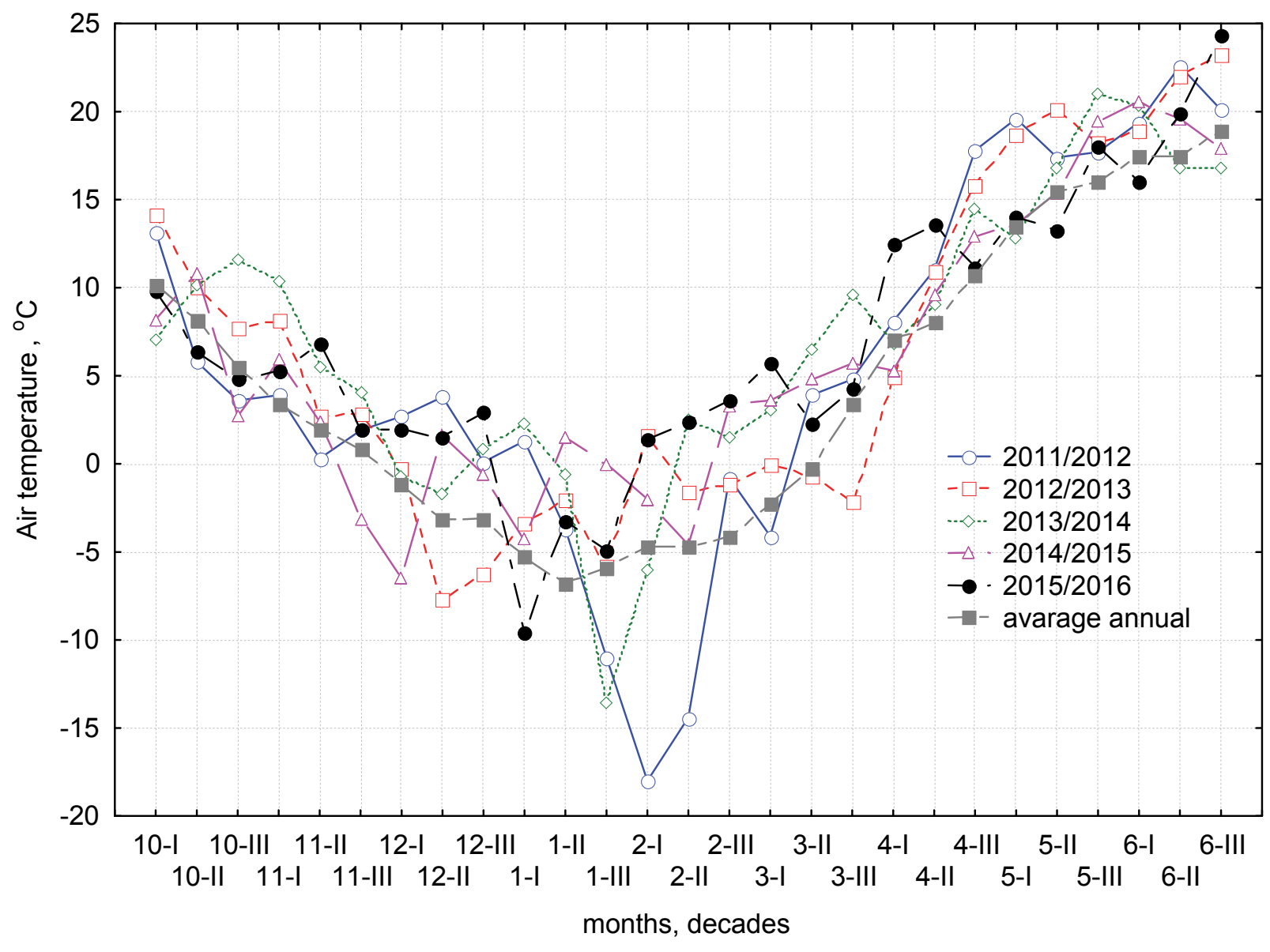

Fig. 1. Average ten-days air temperature during growing season of winter barley, MIW, 2011-2016. 


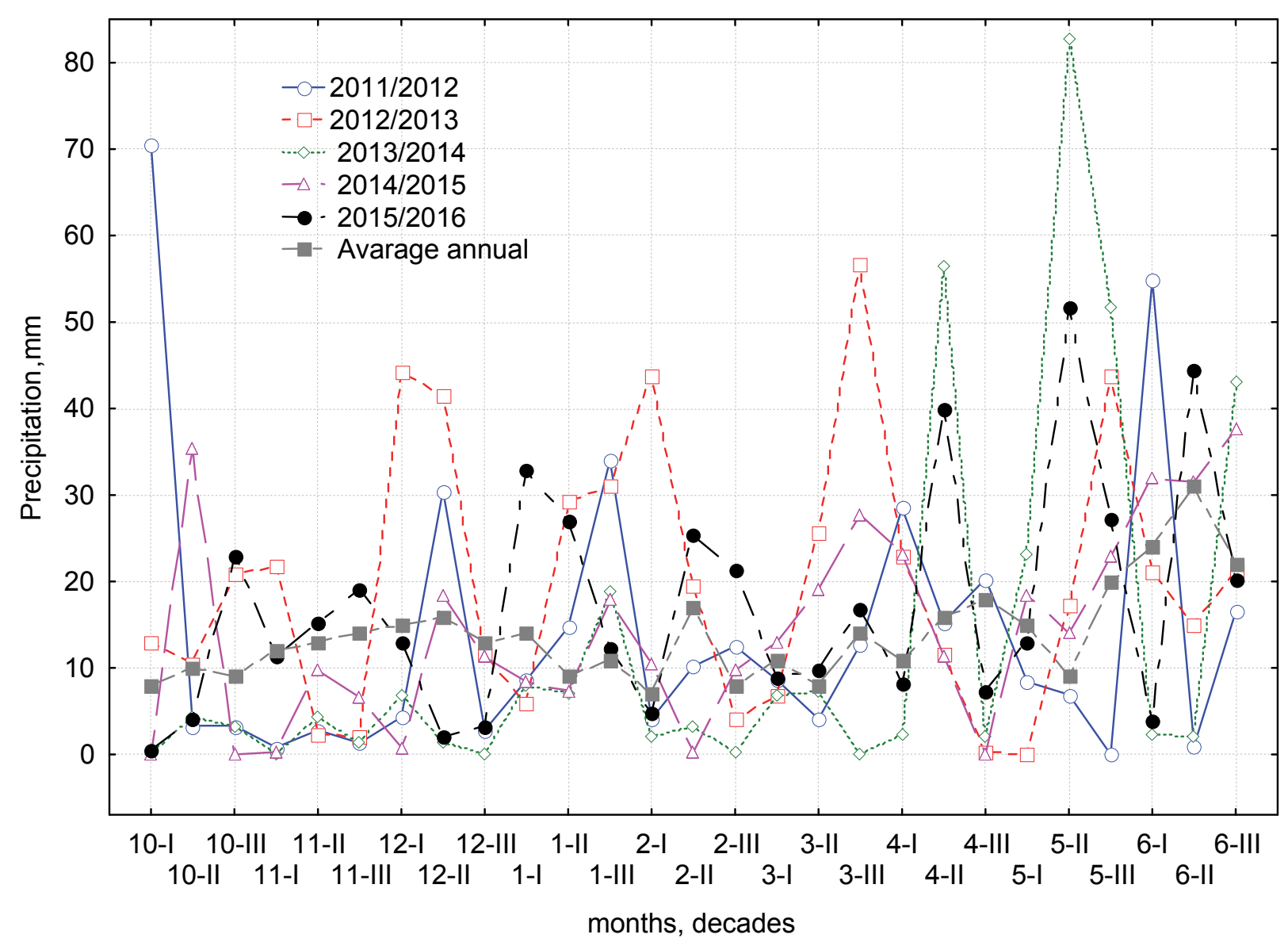

Fig. 2. Every ten days precipitation during cropping season of winter barley, MIW, 2011-2016

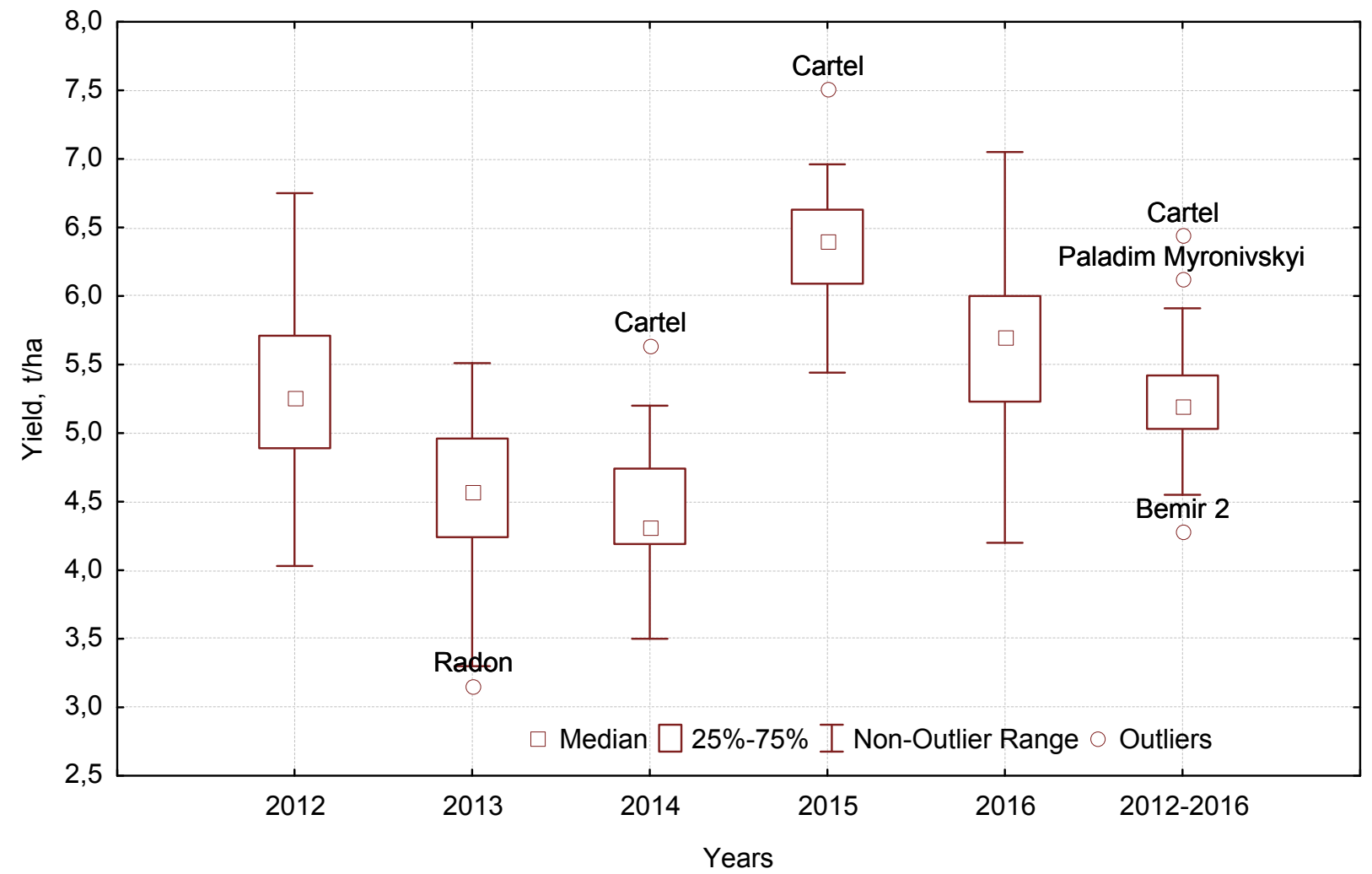

Fig. 3. Expression level of yield of winter barley genotypes, 2012-2016 
The expression level of plant height of the varieties studied also significantly varied through the years. The mean $(X)$, minimum $(\mathrm{min})$ and maximum $(\max )$ values for the experiment were in $2012: X 85.2 \mathrm{~cm}$, $\min 71.0 \mathrm{~cm}$, $\max 96 \mathrm{~cm}$; in 2013: X $76.3 \mathrm{~cm}, \min 64.0 \mathrm{~cm}, \max 93 \mathrm{~cm}$; in 2014: X $104.6 \mathrm{~cm}$, $\min 91.0$ $\mathrm{cm}$, $\max 122.0 \mathrm{~cm}$; in 2015: X $104.7 \mathrm{~cm}$, $\min 85.0 \mathrm{~cm}$, $\max 120.0 \mathrm{~cm}$; in $2016: X 108.3 \mathrm{~cm}$, $\min 92.0 \mathrm{~cm}$, $\max 129.0 \mathrm{~cm}$.

During the years of research, plant lodging was observed annually. Its highest degree was noted in 2016 and 2014 when the average score for the experiment was 3.45 and 4.66 respectively; the lowest degree 7.52 was noted in 2012. In 2013, this value was 6.79, in 2015 - 5.24. For lodging resistance it should be noted tworowed varieties Salamandra, Wintmalt, Maskara, Nektaria, Atlant Myronivskyi and multi-row ones Cartel, Paladin Myronivskyi. The variety Cartel is particularly distinguished having both the highest resistance score (8.8) on average over the years of research and the least its variation $(V=5.1 \%)$.

Expression level and variation of yield, plant height and lodging resistance in winter barley genotypes, 2012-2016.

\begin{tabular}{|c|c|c|c|c|c|c|c|c|c|c|c|c|}
\hline \multirow{2}{*}{ Variety } & \multicolumn{4}{|c|}{ Yield t/ha* } & \multicolumn{4}{|c|}{ Plant height, $\mathrm{cm}$} & \multicolumn{4}{|c|}{ Lodging resistance, score } \\
\hline & $x$ & $\min$ & $\max$ & $\mathrm{V}, \%$ & $x$ & $\min$ & $\max$ & V, \% & $x$ & $\min$ & $\max$ & V, \% \\
\hline Zherar-St & 5.54 & 4.55 & 6.25 & 13.4 & 96 & 81 & 114 & 14.5 & 5.4 & 4 & 8 & 31.0 \\
\hline Cartel & 6.44 & 5.51 & 7.51 & 13.5 & 90 & 75 & 101 & 13.4 & 8.8 & 8 & 9 & 5.1 \\
\hline Paladin & 6.12 & 5.15 & 6.96 & 14.3 & 95 & 74 & 104 & 14.1 & 6.8 & 5 & 9 & 21.8 \\
\hline Atlant & 5.91 & 5.12 & 6.65 & 11.6 & 95 & 77 & 107 & 14.1 & 7.0 & 5 & 9 & 20.2 \\
\hline Salamandra & 5.54 & 4.28 & 6.51 & 16.7 & 84 & 65 & 97 & 16.3 & 7.8 & 6 & 9 & 16.7 \\
\hline MYR 93 & 5.52 & 4.84 & 6.35 & 11.4 & 101 & 83 & 116 & 13.1 & 6.0 & 4 & 8 & 26.4 \\
\hline MYR 87 & 5.48 & 4.43 & 6.87 & 16.9 & 102 & 85 & 114 & 13.2 & 3.8 & 2 & 7 & 65.5 \\
\hline Tutankhamon & 5.42 & 4.50 & 6.35 & 13.1 & 104 & 80 & 120 & 15.3 & 4.4 & 2 & 6 & 41.3 \\
\hline Mascara & 5.41 & 4.17 & \begin{tabular}{|l|}
6.63 \\
\end{tabular} & 17.0 & 82 & 64 & 98 & 17.4 & 8.0 & 5 & 9 & 21.7 \\
\hline Nektaria & 5.39 & 4.31 & 6.47 & 17.6 & 85 & 64 & 97 & 17.2 & 7.8 & 5 & 9 & 22.9 \\
\hline Osnova & 5.36 & 4.23 & 6.25 & 14.6 & 104 & 91 & 119 & 11.5 & 5.4 & 2 & 8 & 40.6 \\
\hline Borysfen & 5.31 & 4.15 & 6.62 & 18.2 & 98 & 80 & 109 & 11.9 & 4.8 & 2 & 7 & 45.2 \\
\hline Luxor & 5.28 & 4.35 & 6.85 & 20.4 & 95 & 73 & 109 & 18.1 & 5.2 & 2 & 8 & 56.7 \\
\hline Kromoz & 5.27 & 4.46 & \begin{tabular}{|l|}
6.04 \\
\end{tabular} & 13.8 & 92 & 72 & 110 & 17.1 & 6.2 & 3 & 8 & 31.0 \\
\hline Seim & 5.20 & 4.21 & \begin{tabular}{|l|}
6.47 \\
\end{tabular} & 18.2 & 106 & 79 & 129 & 19.0 & 4.6 & 3 & 7 & 39.5 \\
\hline Zuben & 5.19 & 4.25 & 6.04 & 14.3 & 103 & 75 & 122 & 18.7 & 4.2 & 2 & 6 & 39.1 \\
\hline Manas & 5.14 & 4.16 & 6.14 & 15.7 & 100 & 80 & 117 & 15.0 & 5.4 & 4 & 7 & 24.8 \\
\hline Pallidum 77 & 5.13 & 4.82 & 6.09 & 10.5 & 97 & 79 & 115 & 14.3 & 3.8 & 2 & 7 & 65.5 \\
\hline Tsyklon & 5.12 & 4.19 & 6.70 & 18.7 & 95 & 81 & 105 & 12.5 & 5.4 & 2 & 7 & 38.4 \\
\hline Kovcheh & 5.09 & 3.77 & 6.49 & 22.4 & 99 & 77 & 118 & 17.5 & 5.0 & 3 & 7 & 31.6 \\
\hline Taman & 5.09 & 4.21 & 6.23 & 15.8 & 93 & 70 & 110 & 16.8 & 4.2 & 2 & 7 & 45.8 \\
\hline Rytsar & 5.03 & 3.50 & 6.77 & 26.4 & 90 & 73 & 103 & 15.4 & 4.0 & 2 & 7 & 58.6 \\
\hline OD 165 & 5.00 & 4.16 & 6.07 & 16.2 & 99 & 77 & 112 & 16.4 & 4.6 & 2 & 8 & 50.0 \\
\hline Wintmalt & 5.00 & 3.94 & 5.74 & 15.3 & 84 & 66 & 98 & 15.1 & 8.0 & 6 & 9 & 17.7 \\
\hline Yuhodar & 4.96 & 4.03 & 6.07 & 14.8 & 96 & 82 & 112 & 13.4 & 6.4 & 5 & 8 & 17.8 \\
\hline Oneha & 4.88 & 4.20 & \begin{tabular}{|l|}
6.44 \\
\end{tabular} & 18.8 & 89 & 69 & 103 & 16.5 & 5.6 & 3 & 7 & 27.1 \\
\hline Radon & 4.66 & 3.16 & 6.40 & 27.4 & 96 & 76 & 112 & 15.9 & 4.0 & 2 & 8 & 70.7 \\
\hline Rosava & 4.55 & 3.65 & 5.81 & 18.1 & 103 & 88 & 122 & 13.5 & 3.6 & 2 & 6 & 50.5 \\
\hline Bemir 2 & 4.28 & 3.30 & 5.44 & 20.2 & 98 & 75 & 107 & 14.2 & 4.2 & 2 & 8 & 72.2 \\
\hline$X$ & 5.25 & 4.26 & 6.39 & 16.7 & 96 & 76 & 111 & 15.3 & 5.5 & 3 & 8 & 37.8 \\
\hline Min & 4.28 & 3.16 & 5.44 & 10.5 & 82 & 64 & 97 & 11.5 & 3.6 & 2 & 6 & 5.1 \\
\hline Max & 6.44 & 5.51 & 7.51 & 27.4 & 106 & 91 & 129 & 19.0 & 8.8 & 8 & 9 & 72.2 \\
\hline
\end{tabular}

Note: here and below $\mathrm{X}$, min, max respectively - average, minimum and maximum value of the trait; $\mathrm{V}$ - coefficient of variation, $\%$.

The matrix of mean values and intercorrelations between the three traits for 2012-2016 in the varieties studied is shown in Fig. 4. Statistical analysis showed no correlation between crop yield and plant height $(r=-0.1044 ; p=0.5898)$. In addition, positive correlation was found between crop yield and lodging 
resistance $(r=0.5880 ; p=0.0008)$, as well as negative correlation between lodging tolerance and plant height $(r=-0.6697 ; p=0.00007)$.
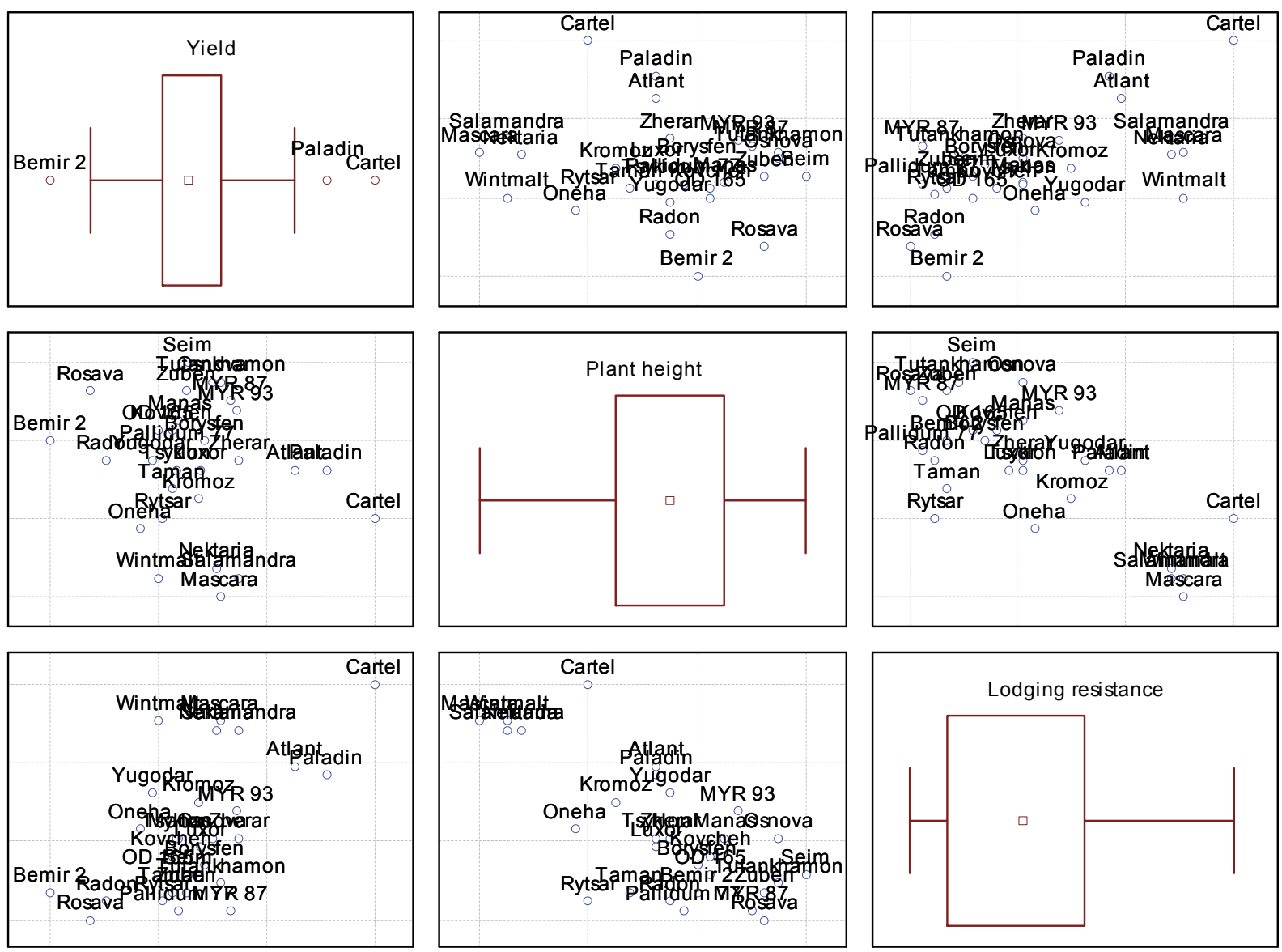

Fig. 4. Relations of expression level of yield, plant height and lodging resistance in winter barley genotypes, average for 2012-2016.

For this set of winter barley varieties, the varieties with an average $(X)$ level of plant height over the years up to $90 \mathrm{~cm}$ and maximum (max) up to $100 \mathrm{~cm}$ are the most resistant to lodging. As the plant height is increased when comparing with the above, lodging resistance noticeably decreases. At the same time, a significant decrease in plant height as compared to the optimal parameters established is also undesirable, as it may be associated with a decrease in yield and adaptability [11]. In turn, it should be noted that for multi-row varieties even in the limits mentioned above genotypes are presented which differ significantly in their lodging resistance. As an example these are the variety Cartel with plant height of 90 $\mathrm{cm}$ and lodging resistance 8.8.; Oneha, respectively $-89 \mathrm{~cm}, 5.6$; Rytsar $-90 \mathrm{~cm}, 4.0$. This is due to the fact that in addition to plant height the lodging resistance is also determined by the number of some anatomical and morphological features [12-13]. A special publication will be devoted to detailed review of the level of manifestation and the ratio of the features.

\section{Conclusions}

Under environments of the Forest-Steppe of Ukraine, based on the experimental research and mathematical-statistical analysis conducted it has been proved the necessity and possibility of combining high yielding level with the simultaneous gradual decrease of plant height and increase of lodging resistance in novel new winter barley varieties.

There have been identified genotypes Cartel, Paladin Myronivskyi, Atlant Myronivskyi that significantly exceed the national standard by the level of yield and combine it with higher as compared with other varieties degree of lodging resistance. Taking into account that the latter two are included in the State Register of Ukraine, they are recommended to be introduced at the agricultural enterprises of the ForestSteppe of Ukraine. The multi-row variety Cartel is a valuable genetic source of the optimal combination of the traits mentioned above and is advisable to use in breeding programs to create the next level source of 
winter barley. To create two-rowed winter barley varieties with increased lodging resistance it is necessary to involve the varieties Salamandra, Maskara, Nektaria.

\section{References}

1. Gudzenko V.M. Yield, plasticity and stability of winter barley in the central Forest-Steppe of Ukraine. Plant Breeding and Seed Production. 2013; 103: 231-241.

2. Linchevskyi A.A. 95 years of barley breeding at the Plant Breeding \& Genetics Institute. Collected scientific articles of PBGI-NCSCI. 2012; 20: 66-83.

3. Zhuchenko A.A. Ecological Genetics of Cultivated Plants and Problems of the Agrosphere (Theory and Practice). Moscow: Agrorus; 2004. 1166 p.

4. Lytvynenko M.A., Rybalka O.I. Grain Crops. The state and prospects for the creation of new varieties and hybrids at the scientific institutions of the Ukrainian Academy of Agricultural Sciences. Seed Production. 2007; 1: 3-6.

5. Gudzenko V.N. Results of winter barley breeding at the V. N. Remeslo Mironovka Institute of Wheat of NAAS of Ukraine. Agriculture and Plant Breeding in Belarus. 2013; 49: 398-405.

6. Ivashchenko O.O., Rudnyk-Ivashchenko O.I. Directions of adaptation of agrarian production to climate fluctuations. News of Agrarian Sciences. 2011; 8: 10-12.

7. Shubenko I.A., Zhuravlyeva N.P. Winter barley resistance to lodging. Some reserves to increase grain production in Ukraine: Collected scientific works. Kiev: Urozhay. 1995. P. 106-115.

8. Lukyanova I.V. Analysis of species and varietal features of lodging resistance in cereal crop stems with taking into account their physical and mechanical properties and architectonics for use in breeding: Thesis abstract for Doctor Sci (Biology). Krasnodar; 2009. 51 p.

9. Gudzenko V.M. Plant breeding value of winter barley collection samples under environments of Forest-Steppe of Ukraine. Agrobiology. 2014; 2: 29-33.

10. Methodology of State Strain Testing of Crops. Tyiv; 2000. 100 p.

11. Isamitdinov R.N. The use of anatomical and morphological features of the stem in winter barley breeding for lodging resistance: Thesis abstract for Candidate of Science (Agriculture). Krasnodar; 2010. $24 \mathrm{p}$.

12. Saranchin Ye.P. Morphological features of shoot, the nature of variability and inheritance of traits short-stem barley varieties related to lodging resistance: Thesis abstract for Candidate of Science (Biology). St. Petersburg: VIR; 2005. 22 p.

13. Jezowski S., Surma M., Adamski T., Krajewski P., Głowacka K. Genetic analysis of morphological and physical stem characteristics determining lodging resistance in two- and six-rowed barley (Hordeum vulgare L.) lines. Int. Agrophysics. 2005; 19(4): 299-303. 